\title{
Article \\ Integration of Renewable Based Distributed Generation for Distribution Network Expansion Planning
}

\author{
Mulusew Ayalew ${ }^{1}$, Baseem Khan ${ }^{1} \mathbb{1}$, Issaias Giday ${ }^{1}$, Om Prakash Mahela ${ }^{2, *} \mathbb{D}$, Mahdi Khosravy ${ }^{3, * \mathbb{C}}$, \\ Neeraj Gupta ${ }^{4}$ and Tomonobu Senjyu ${ }^{5}$ (i) \\ 1 Department of Electrical and Computer Engineering, Hawassa University, Hawassa 1530, Ethiopia; \\ muluethio21@gmail.com (M.A.); baseem.khan04@gmail.com (B.K.); isuag7@gmail.com (I.G.) \\ 2 Power System Planning Division, Rajasthan Rajya Vidyut Prasaran Nigam Ltd., Jaipur 302005, India \\ 3 Cross Labs, Cross-Compass Ltd., Tokyo 104-0045, Japan \\ 4 Computer Science and Engineering Department, Oakland University, Rochester, NY 48309, USA; \\ neerajgupta@oakland.edu \\ 5 Faculty of Engineering, University of the Ryukyus, Okinawa 903-0213, Japan; b985542@tec.u-ryukyu.ac.jp \\ * Correspondence: opmahela@gmail.com (O.P.M.); dr.mahdi.khosravy@ieee.org (M.K.)
}

Citation: Ayalew, M.; Khan, B.; Giday, I.; Mahela, O.P.; Khosravy, M.; Gupta, N.; Senjyu, T. Integration of Renewable Based Distributed Generation for Distribution Network Expansion Planning. Energies 2022, 15, 1378. https://doi.org/ $10.3390 /$ en15041378

Academic Editor: Jung-Wook Park

Received: 29 December 2021

Accepted: 12 February 2022

Published: 14 February 2022

Publisher's Note: MDPI stays neutral with regard to jurisdictional claims in published maps and institutional affiliations.

Copyright: (c) 2022 by the authors Licensee MDPI, Basel, Switzerland. This article is an open access article distributed under the terms and conditions of the Creative Commons Attribution (CC BY) license (https:// creativecommons.org/licenses/by/ $4.0 /)$.

\begin{abstract}
Electrical energy is critical to a country's socioeconomic progress. Distribution system expansion planning addresses the services that must be installed for the distribution networks to meet the expected load need, while also meeting different operational and technical limitations. The incorporation of distributed generation sources (DGs) alters the operating characteristics of modern power systems, resulting in major economic and technical benefits, such as simplified distribution network expansion planning, lower power losses, and improved voltage profile. Thus, in this study, an analytical method is used to design the expansion planning of the Addis North distribution network considering the integration of optimal sizes of distributed generations for the projected demand growths. To evaluate the capability of the existing Addis North distribution network and its capability to supply reliable power considering future expansion, the load demand forecast for the years 2020-2030 is done using the least square method. The performance evaluation of the existing and the upgraded network considering the existing and forecasted load demand for the years 2030 is done using ETAP software. Accordingly, the results revealed that the existing networks cannot meet the existing load demand of the town, with major problems of increased power loss and a reduced voltage profile. To mitigate this problem, the Addis North feeder-1 distribution network is upgraded and for each study case, the balanced and positive sequence load flow analysis was executed and the maximum total real and reactive power losses were found at bus 29 . The result shows that the upgraded network of bus 29 was the optimal location of DG and its size was 9.93 MW. After the optimal size of DG was placed at this bus, the real and reactive power losses of the upgraded networks were 0.2939 MW and 0.219 MVAr, respectively. At bus 29 the maximum power losses reduction and voltage profile improvements were found. The active and reactive power losses were minimized by $21.285 \%$ and $19.633 \%$ respectively and the voltage profiles were improved by $8.78 \%$. Thus, in the predicted year 2030 , DG power sources could cover $61.12 \%$ of the feeder- 1 power requirements.
\end{abstract}

Keywords: analytical method; voltage profile improvement; planning

\section{Introduction}

Generation units, transmission, and sub-transmission networks, distribution systems, consumption centers, protection equipment, and control devices are all common elements of an electrical network [1]. The distribution substations supply electrical energy to the end-user consumers and it is an essential part of the power systems. Substations and feeder branches are the major components of the distribution network. Although distribution substations are sometimes directly connected to the transmission network, they are fed via one or more sub-transmission networks. One of the key operations of distribution 
utilities to deal with rising electric power demand is the expansion planning of power distribution networks.

The fundamental goal of distribution network expansion planning (DNEP) is to offer consumers a dependable and cost-effective solution while providing constant voltages and power quality [2]. This aim is usually obtained by fortifying current infrastructure and substations or adding additional ones due to technical and operational restrictions [3,4].

The economic and operational context of the electricity system has evolved as new capacity alternatives have arisen. One of these new choices is distributed generation (DG). The addition of DG to the power system alters the operational characteristics and provides major technical and economic benefits. When DG sources are included in the planning alternatives, the distribution network's functioning, structure, design, and expansion difficulties are all affected. DG applications currently utilize a variety of technologies, ranging from classic to non-traditional. Internal combustion engines, coupled cycles, gas turbines, and micro-turbines are examples of non-renewable technologies. Wind, solar, biomass, and geothermal, are examples of renewable-energy technologies that participate in DG. The distribution network is being converted from a passive to an active network due to the accessibility of such a flexible alternative as DG as a power resource at the distribution voltage level [5].

The distribution equipment becomes overloaded due to the rapid load growth rates and it is not easy to replace the overloaded power system devices due to its high investment costs. As the economic pressure to fully utilize the capacity of current power equipment grows, new types of incentive schemes, such as permanent demand reduction, load curtailment/shifting, distribution generation (DG), and others, have been developed to reduce peak demand. To increase the customers' electric energy satisfaction, appropriate planning is needed from the electrical utilities. Utilities have taken notice of this trend, and DG considerations have been incorporated into the planning and operation of distribution systems. DG has the capability to increase reliability and supply quality, minimize power losses, and minimize the transmission and distribution construction expenditures with optimal DG location [6].

Electricity is generated by large-scale power plants and transmitted to end-consumers via transmission and distribution networks in typical power networks. This is referred to as a centralized generation. Customers or utility companies install small-scale generators on low-voltage networks as part of distributed generation or decentralized generation. DG is made up of small-scale power stations located near demand centers. Wind turbines, photovoltaic (PV) plants, micro-hydro plants, fuel cells, and energy storage devices, such as batteries are all examples of current DG technologies [6].

\section{Related Work}

The DNEP is done to ensure that enough power is available to meet all of the customers' current and future load requirements. The existing distribution network infrastructure expansions must be shaped, reconfigured, and developed with the suitable electrical requirements of the customers, according to expansion planning. Distribution network planners' key responsibilities are to discover predicted load capacity, develop enough distribution network capacity, and keep all distribution network components within acceptable capacity limits.

Ref. [7] describes a multi-year DG-integrated system for distribution network expansion planning that is using a binary chaotic shark smell optimization algorithm. This study investigates and solves MEPDN (multi-year distribution network expansion planning) for the best growth of the primary distribution network to position and size the DG, as well as reinforce the primary distribution feeders in the projected term. Furthermore, in order to improve network resilience, an analytical technique based on minimal load shedding has been implemented to reduce total investment and operation expenses. In addition, binary chaotic shark smell optimization (BCSSO) was used to address the distribution network's multi-year expansion plans. Ref. [8] investigated optimal expansion planning of 
distribution system capacity with regard to distributed generations. This paper proposes a binary particle swarm optimization (PSO)-based heuristic evolutionary algorithm for solving single and multi-objective distribution system expansion planning problems, as well as DG and the traditional method. The voltage deviation, power loss, location, and size of DG units are employed as objective functions in the particle swarm optimization cost function. A multi-objective PSO algorithm for distribution network expansion planning was proposed by the authors of [9]. In this paper, distribution network expansion planning is performed to minimize investment and operation costs and energy loss costs. The multi-objective PSO and two-phase multi-objective PSO have been put to the test on the 18-bus network to see if they are viable and effective. The authors of [10] recommended planning for the distribution system expansion in a deregulated context with system uncertainty. The Monte Carlo simulation-based long-term distribution system planning model is investigated and tested in a competitive setting, taking into consideration technological and economic constraints. The proposed planning takes into account network equipment, experimental decisions, not-supplied energy costs, DG investments, environmental emissions, and component supply and demand forecasting uncertainties.

The authors of [11] used particle swarm optimization to evaluate the location of dispersed generators for loss minimization and voltage augmentation. In this paper, photovoltaic cells, and synchronous compensator are used as a DG and their optimal sizes and locations were obtained to minimize power losses and improve voltage profiles. Although it is good that they have incorporated the cost-effectiveness of distributed generation integration in their objectives, they have left out branch current carrying capacity and reactive power loss. The author of [12] proposed a novel DG planning approach with the goal of increasing renewable-based DG penetration while lowering annual losses. Reactive power planning and network reconfiguration are used in this paper to optimize DG penetration and reduce yearly DG losses while taking into account feeder capacity, short circuit level, and investment cost restrictions. To tackle the optimization problem, the PSO algorithm multi-objective method is used, and 96 scenarios and 10 various network load levels are investigated.

Particle swarm-based power loss mitigation and voltage profile optimization of a distribution system using distributed generation was presented in [13]. On the Iraqi 30-bus distribution grid, the claimed method was evaluated, and the real power loss was reduced by 39.67 percent. Although the result obtained is encouraging, if network reconfiguration was undertaken after integrating distributed generations into the existing distribution system, the power losses might be significantly minimized. The author of [14] focuses on the optimum sizing of distributed generation using particle swarm optimization to increase distribution network performance. By minimizing active power loss and improving the voltage profile of each bus in the system, optimal location and sizing play a significant role in enhancing system efficiency. The proposed technique was tested using IEEE 15 Bus and IEEE 33 Bus radial distribution systems. In terms of system loss reduction and voltage profile improvement, the NPSO optimized system beats both the PSO optimized and non-optimized systems. This study found no evidence of the impact of renewable DG on network reliability. The authors of [15] proposed that keeping the voltage profile at the appropriate value will minimize power loss and running costs. By combining the loss sensitivity factor, the operational cost of installing distributed generation and the voltage stability index, a hybrid particle swarm optimization (HPSO) is employed to allocate distributed generation effectively. Weighting factors are used to create the goal function. The forward-backward technique is used to analyze load flow. The method was tested using IEEE 33 and 69 bus radial distribution networks. The HPSO technique converges quickly when compared to the genetic algorithm and particle swarm optimization. When compared to the preceding procedures, this strategy produces a better result. Environmental issues and reactive power loss are not investigated. The influence of distributed generation on the short circuit current level of protective devices was not examined in this study. In [16], the author uses the Moth-Flame Optimization algorithm and the loss sensitivity factor 
to construct an effective hybrid solution for optimal DG allocation in radial distribution networks (LSF). The study's purpose was to reduce power loss, enhance voltage profile, and increase voltage stability by optimizing PV and wind-based DG siting and sizing. The proposed approach was tested on standard IEEE 33 and 69 bus radial distribution systems. PV and wind-based DG improve system performance, according to the findings. The stochastic character of wind speed and sun irradiation was not considered in this study. The impact of solar and wind-powered DG on system reliability was not studied. Based on the voltage limitation index (VLI), the authors discuss the placement and size of DG in [17]. This index ensures that all buses in the network have a voltage profile that is acceptable within the distribution's allowed limits. Following the determination of the DG size and position, a full analysis of the cost of DG, energy loss, and network savings was performed. The author of [18] used a combination of GA and IPSO to optimize the DG site and size while accounting for both real and reactive power losses. Real power, reactive power flow, and power loss sensitivity variables are used to determine the candidate buses for DG allocation. This literature has the benefit of shrinking the algorithm's search space and enhancing its rate of convergence. However, because of the large iteration time, more work can be done to try to lower it. The authors introduced the genetic algorithm and improved particle swarm optimization (GAIPSO) for optimal DG placement and sizing for power loss reduction and voltage profile enhancement in [19]. GA-IPSO was used to determine the ideal location and size for a DG, taking into consideration both real and reactive power losses. Real and reactive power, as well as power loss sensitivity factors, was used to identify candidate buses for DG allocation. However, by considering other power system elements, such as system update issues, the multi-objective function can be enhanced. Ref. [20] proposed a novel DG planning approach with the goal of increasing renewable-based DG adoption while lowering annual losses. Reactive power planning and network reconfiguration are used in this paper to optimize DG penetration and reduce yearly DG losses while taking into account feeder capacity, short circuit level, and investment cost restrictions.

According to the above works of literature, most of the papers focus on only single problem solutions, such as power loss minimization, voltage profile improvement, and network expansion planning. Additionally, most of the papers focus on IEEE distribution network data.

This paper proposed an analytical method for distribution network expansion planning that takes into account future demand growth and optimal distributed generation sizing and placement. To evaluate the capability of the real existing Addis North distribution network and its capability to supply reliable power considering future expansion, the load demand forecast for the years 2020-2030GC is done using the least square method. The performance evaluation of the existing and the upgraded network considering the existing and forecasted load demand for the years 2030GC is done using ETAP software. Accordingly, the results revealed that the existing networks cannot meet the existing load demand of the town, with major problems of increased power loss and a reduced voltage profile.

\section{Methodology}

A flow chart was used to describe the entire approach of this investigation, which included the following essential steps, as shown in Figure 1.

\subsection{System Modeling and Load Flow Analysis}

The electrical transient analyzer program is used to model the system (ETAP). ETAP [21-26] is used to do a more detailed load flow study. 


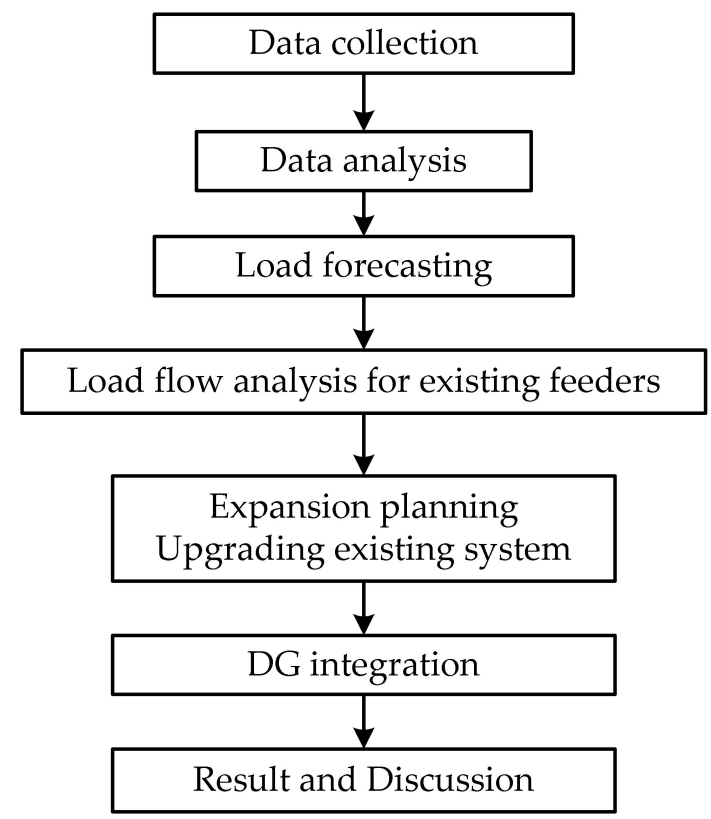

Figure 1. The Overall Methodology.

\subsubsection{Power Loss Calculation}

Line losses can occur on both major and secondary feeders in the distribution system. The square of the current flowing through the resistance $(R)$ and reactance $(X)$ of the line determines line losses. The line losses can be computed as:

$$
\begin{aligned}
& P_{\text {Loss }}=\sum_{\mathrm{i}, \mathrm{j}=1}^{\mathrm{N}}\left(\mathrm{i}_{\mathrm{ij}}^{2} \mathrm{R}_{\mathrm{ij}}\right) \\
& \mathrm{Q}_{\text {Loss }}=\sum_{\mathrm{i}, \mathrm{j}=1}^{\mathrm{N}}\left(\mathrm{i}_{\mathrm{ij}}^{2} \mathrm{X}_{\mathrm{ij}}\right)
\end{aligned}
$$

where, $P_{\text {Loss }}$ is the total active power loss, $Q_{\text {Loss }}$ is the total reactive power loss, $\mathrm{i}_{\mathrm{ij}}$ is branch current flowing from bus $i$ to bus $j, R_{i j}$ is line resistance between bus $i$ and bus $j$ and $X_{i j}$ is the line reactance between bus $i$ and bus $j$.

\subsubsection{Voltage Drop}

The voltage drop in the radial feeder is caused by the feeder's line impedance, which covers a long distance in the network. Due to the low voltage and excess current caused by this voltage drop, it may have a negative impact on the equipment or appliances that are connected to the utility [27]. Figure 2 shows the distribution system as a single-line figure.

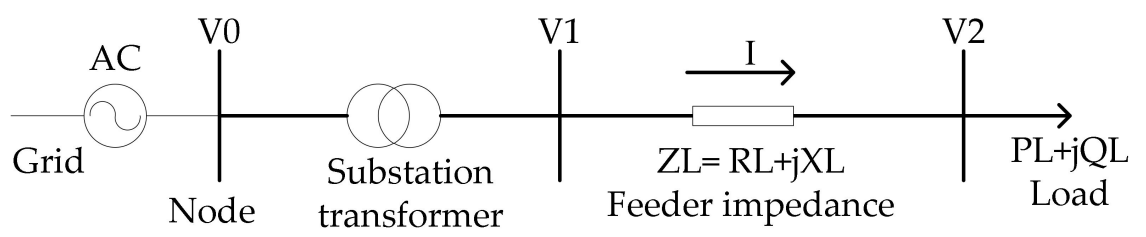

Figure 2. Single-line diagram of distribution system.

The voltage drop can be calculated as follows when the radial feeder is relatively lengthy and feeds non-uniformly distributed loads as the primary feeder supply from one to several transformers:

$$
\begin{gathered}
I=\left(\frac{S}{V_{2}}\right)^{*} \\
I=\left(\frac{P_{L}-j Q_{L}}{V_{2}}\right)^{*}
\end{gathered}
$$


The voltage drop due to the distribution line only is:

$$
\begin{gathered}
V_{1}-V_{2}=I\left(R_{L}+j X_{L}\right)=\left(\frac{P_{L}-j Q_{L}}{V_{2}^{*}}\right) *\left(R_{L}+j X_{L}\right) \\
V_{1}-V_{2}=\left(\frac{\left(P_{L} R_{L}+Q_{L} X_{L}\right)-j\left(P_{L} X_{L}-Q_{L} R_{L}\right.}{V_{2}}\right)
\end{gathered}
$$

where, $\mathrm{P}_{\mathrm{L}}$ and $\mathrm{Q}_{\mathrm{L}}$ are real and reactive loads, respectively, and $\mathrm{V}_{1}$ and $\mathrm{V}_{2}$ are grid and load voltages, respectively.

\subsubsection{Conductor Size Selection}

In the Addis North distribution network, the strands of an all-aluminum conductor (AAAC) were commonly employed. Their size was determined by the current's maximum carrying capacity.

In order to address the selection of conductor sizes for the expansion of the future Addis North distribution network, a load flow study was conducted using ETAP. The conductors' allowed current carrying capacity (Ip) can then be used to determine the size of the feeder conductors as $\mathrm{I} \leq \mathrm{I}_{\mathrm{P}}$.

The following formula is used to determine the maximum current in a feeder:

$$
\mathrm{I}_{\mathrm{p}}=\frac{\mathrm{P}}{\sqrt{3} * \mathrm{~V} * \cos \theta}
$$

where, $\mathrm{P}$ is the maximum power in the feeder $(\mathrm{kW}), \mathrm{V}$ is the base voltage of the feeder $(\mathrm{kV})$, $\mathrm{I}_{\mathrm{p}}$ is peak current (the proposed conductor maximum current carrying capacity) and $\cos \theta$ is the power factor of the feeder.

\subsubsection{Transformer Size Selection}

To determine the size of the transformer, the value of demand of the LV network transformers is calculated, taking into consideration the load that was connected to the secondary main. After the load has been estimated, the "next bigger" EEU standard transformer size is chosen, which is normally larger than the demand to allow for future development and not to have a negative influence on the transformer's life [28,29].

$$
\mathrm{S} \text { selected } \geq \mathrm{S} \text { demand (KVA) }
$$

\subsection{Distributed Generation Sizing and Placement}

Though the voltage drops and power loss in the distribution system are inherent problems, as is discussed before, they cannot be completely removed. The best DG allocation method can significantly improve the voltage profile and reduce power losses.

There are various advantages to installing distribution generation units in strategic locations throughout a distribution system. Line losses will be decreased, the voltage profile will be improved, environmental impacts will be reduced, total energy efficiency will be improved, and investments in current generating, transmission and distribution systems will be lowered. The optimal sizes and location of DG are formulated in the coming Section 2.2.1.

\subsubsection{Problem Formulation}

The following equations [30] calculate the power loss when a DG is deployed at any point in the network, as shown in Figure 3. 


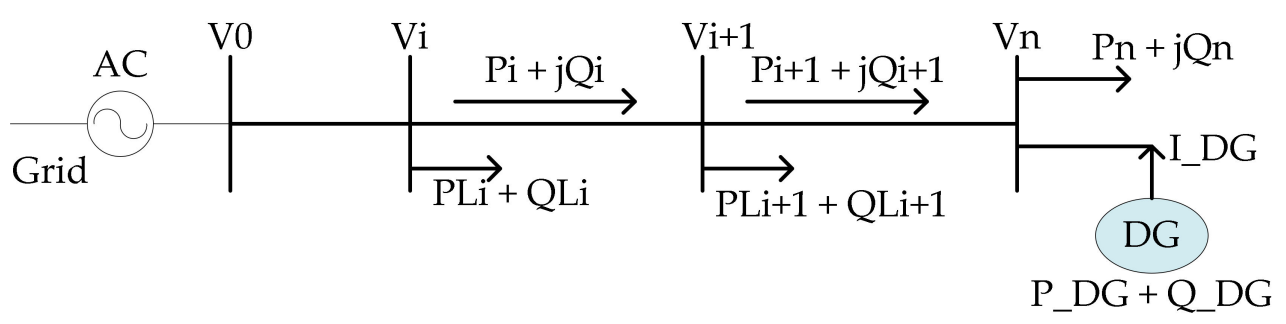

Figure 3. Distribution network with DG connection.

The active and reactive power losses before the installation of DG are given in the equations below.

$$
\begin{gathered}
P_{i+1}=P_{i}-P_{L o s s, i}-P_{L i+1} \\
=P i-\frac{R_{i}}{V_{i}^{2}}\left(P_{i}^{2}+Q_{i}^{2}\right)-P_{L i+1} \\
Q_{i+1}=Q_{i}-Q_{L o s s, i}-Q_{L i+1} \\
=Q_{i}-\frac{X_{i}}{V_{i}^{2}}\left(P_{i}^{2}+Q_{i}^{2}\right)-Q_{L i+1}
\end{gathered}
$$

The power loss in the line between buses $i$ and $i+1$ can be calculated as follows:

$$
\begin{aligned}
& P_{\text {loss }}(i, i+1)=\frac{R_{i}}{V_{i}^{2}}\left(P_{i}^{2}+Q_{i}^{2}\right) \\
& Q_{\text {loss }}(i, i+1)=\frac{X_{i}}{V_{i}^{2}}\left(P_{i}^{2}+Q_{i}^{2}\right)
\end{aligned}
$$

The overall power losses of the feeder, $\mathrm{P}_{\text {loss, }}$ and $\mathrm{Q}_{\text {loss }}$ can then be calculated by adding the losses of all feeder line sections, as follows:

$$
\begin{aligned}
& \mathrm{P}_{\mathrm{T}, \text { loss }}=\sum_{\mathrm{i}}^{\mathrm{n}} \frac{\mathrm{R}_{\mathrm{i}}}{\mathrm{V}_{\mathrm{i}}^{2}}\left(\mathrm{P}_{\mathrm{i}}^{2}+\mathrm{Q}_{\mathrm{i}}^{2}\right) \\
& \mathrm{Q}_{\mathrm{T}, \text { loss }}=\sum_{\mathrm{i}}^{\mathrm{n}} \frac{\mathrm{X}_{\mathrm{i}}}{\mathrm{V}_{\mathrm{i}}^{2}}\left(\mathrm{P}_{\mathrm{i}}^{2}+\mathrm{Q}_{\mathrm{i}}^{2}\right)
\end{aligned}
$$

The power loss equations derived above can be adjusted as follows when DG is integrated into the distribution system:

$$
\begin{gathered}
P_{D G \text { loss }}(i, i+1)=\frac{R_{i}}{V_{i}^{2}}\left(P_{i}^{2}+Q_{i}^{2}\right)+\frac{R_{i}}{V_{i}^{2}}\left(P_{D G}^{2}+Q_{D G}^{2}-2 P_{i} P_{D G}-2 Q_{i} Q_{D G}\right) \\
Q_{D G \text { loss }}(i, i+1)=\frac{X_{i}}{V_{i}^{2}}\left(P_{i}^{2}+Q_{i}^{2}\right)+\frac{X_{i}}{V_{i}^{2}}\left(P_{D G}^{2}+Q_{D G}^{2}-2 P_{i} P_{D G}-2 Q_{i} Q_{D G}\right)
\end{gathered}
$$

As a result, the minimization of the multi-objective optimization function is formulated as shown below:

$$
\mathrm{F}_{\min }=\mathrm{W}_{1} \times \sum_{\mathrm{i}=1}^{\mathrm{N}}\left(\mathrm{P}_{\text {, loss }}(\mathrm{i}, \mathrm{i}+1)\right)+\mathrm{W}_{2} \times \sum_{\mathrm{i}=1}^{\mathrm{N}}\left(\mathrm{Q}_{\text {,loss }}(\mathrm{i}, \mathrm{i}+1)\right)+\mathrm{W}_{3} \times \sum_{\mathrm{i}=1}^{\mathrm{N}}\left(1-\mathrm{V}_{\mathrm{i}}\right)^{2}
$$

where, $\mathrm{W}_{1}$ is the weighting factor giving priority for reduction of real power losses, $\mathrm{W}_{2}$ is the weighting factor giving priority for reduction of reactive power losses and $W_{3}$ is the weighting factor giving priority for the reduction of voltage deviation in the radial distribution networks. Weights of objective functions are chosen in proportion to the relative importance of the objectives. This paper is done by giving more emphasis on real power losses and voltage profile improvements. It is also important that the condition 
$\mathrm{W}_{1}+\mathrm{W}_{2}+\mathrm{W}_{3}=1$ has to be satisfied in each case. Thus, in this study, the weight values are assumed as $W_{1}$ is restricted to be in between 0.4 and $0.7, W_{2}$ and are restricted to be in between 0.1 and 0.5 . The weight factors having minimum fitness values are selected for the multi-objective optimization function. Thus, based on these criteria the candidate weight factors were checked with Equation (19) objective functions, and the weights chosen were $\mathrm{W}_{1}=0.6, \mathrm{~W}_{2}=0.1$ and $\mathrm{W}_{3}=0.3$.

\subsubsection{Constraints}

Constraints are a critical consideration in optimization processes. Indeed, an optimal solution satisfies all of the optimization problem's constraints. The following technological constraints are taken into account when locating and sizing the DG in this work.

(a) Voltage limit constraints

All distribution bus voltages should have a fluctuation range that is within a certain range.

$$
\mathrm{V}_{\text {min }}<\mathrm{Vi}^{\mathrm{WDG}}<\mathrm{V}_{\max }
$$

In this work, the $\pm 5 \%$ of the nominal voltage is considered. The nominal voltage of all the buses is assumed to be $15 \mathrm{kV}$.

(b) The size of the 'DG capacities'

The DG units' maximum active power must not exceed the network's load demand + total real power loss.

$$
\mathrm{P}_{\mathrm{DG}} \leq \mathrm{P}_{\text {load }}+\mathrm{P}_{\text {loss }}
$$

(c) The minimum power factor constraint of the DG units

Synchronous generators can produce both active and reactive electricity at the same time. Because electrical companies prefer to operate at higher power factors, this constraint should be taken into account while sizing and siting. The constraint in question is as follows:

$$
0.85 \leq \mathrm{PF}_{\mathrm{DG}}
$$

The power factors of DG are assumed to be 0.85 in this study.

(d) Branch thermal limit constraint

The loading of line segments should not be increased beyond their allowed range by installing DG units. Power providers will have to replace overloaded line segments with larger conductors if this does not happen.

$$
I_{(i, j)} \leq I_{\text {rated }}
$$

$\mathrm{I}_{\text {rated }}$ : thermal current carrying capacity of line section ij.

(e) Power losses constraints

The loss criteria after the integration of DG sources should be as follows:

$$
\left(\begin{array}{l}
\mathrm{P}_{\mathrm{L} \text { with } \mathrm{DG}} \leq \mathrm{P}_{\mathrm{L}} \text { without DG } \\
\mathrm{Q}_{\mathrm{L} \text { with DG }} \leq \mathrm{Q}_{\mathrm{L} \text { without DG }}
\end{array}\right)
$$

To avoid any changes in the distribution network as a result of the installation of DG, all of the work's limits are taken into account.

\subsubsection{Identification of Location of DG}

The analytical MATLAB code determines the optimal sizes and locations of DG using an objective function of Equation (19) and constraint equations of Section 2.2.2. In each scenario, the total power loss and voltage profile of the system are determined using load flow analysis, and the results are saved in order to move on to the next stage. The DG sizes 
and locations having minimum power loss and minimum voltage deviation are saved and considered as optimal results of the problem [31,32].

The flow chart depicting optimal DG sizing and location utilizing analytical MATLAB code and ETAP simulation software is shown in Figure 4.

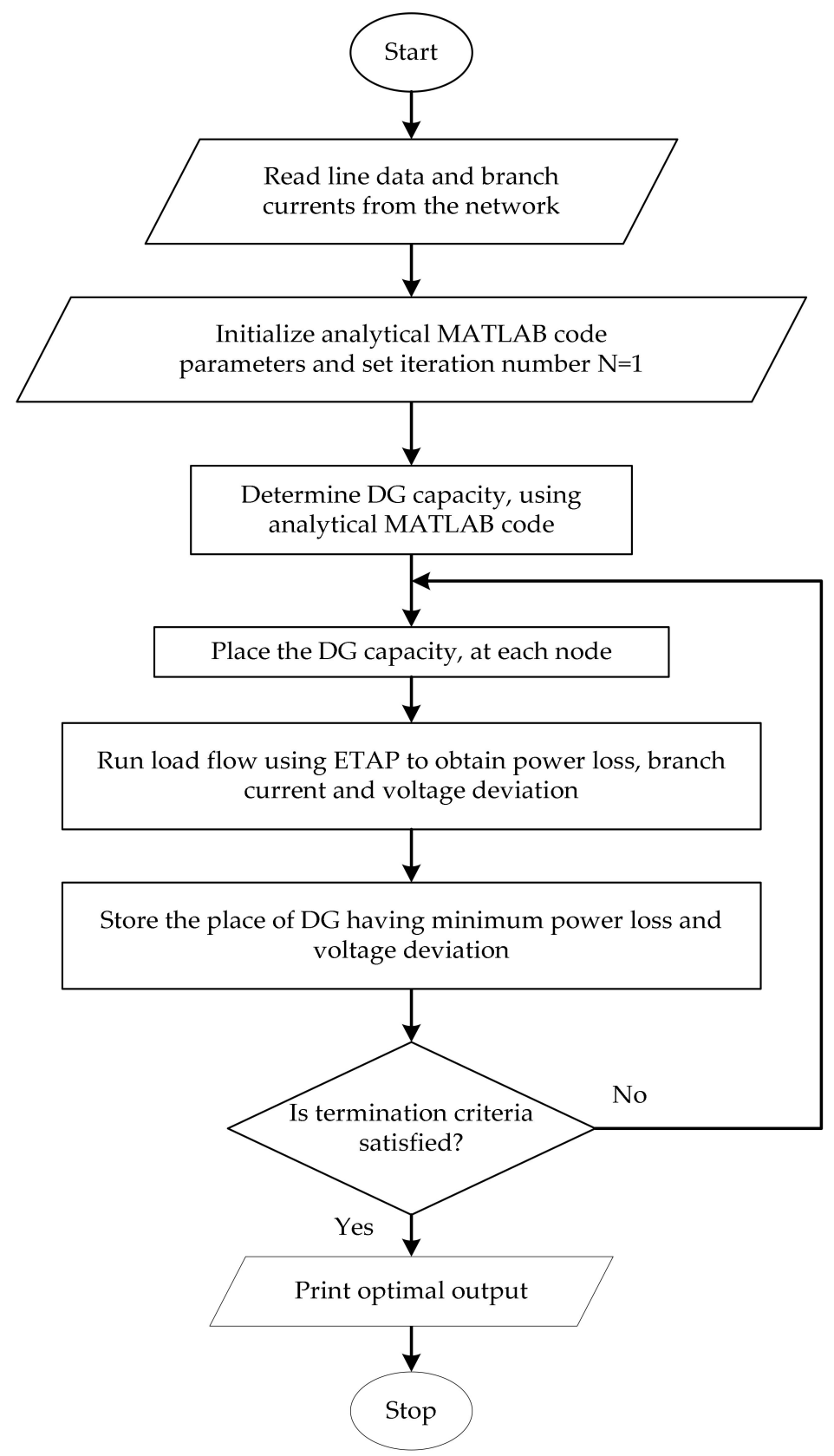

Figure 4. The optimal DG sizing and location diagram.

\subsection{Forecasting of Peak Load}

Linear regression analysis is utilized to develop the forecasting model. According to this theory function, $\mathrm{Y}=\mathrm{f}(\mathrm{x})$ can fit a set of points $(\mathrm{X} 1, \mathrm{Y} 1)$ as $(\mathrm{X} 2, \mathrm{Y} 2)$. For that purpose sum of squared errors is minimized.

$$
\operatorname{Min} \sum_{\mathrm{i}=0}^{\mathrm{n}}\{\mathrm{Yi}-\mathrm{f}(\mathrm{x})\}^{2}
$$

where, $\mathrm{n}$ is the number of data points. 
Using the linear regression method;

$$
\begin{gathered}
Y=f(x) \\
Y i=a_{0}+a_{1} X i \\
e^{2}=\sum_{i=0}^{n}(Y-Y i)^{2} \\
\min \left(e^{2}\right)=\min \sum_{i=0}^{n}\left[Y-\left(a_{0}+a_{1} X i\right)\right]^{2}
\end{gathered}
$$

To compute unknown variables $\mathrm{a}_{0}$ and $\mathrm{a}_{1}$ :

$$
\begin{gathered}
\mathrm{Na}_{0}+\mathrm{a}_{1} \sum \mathrm{Xi}=\sum \mathrm{Y} \\
\mathrm{a}_{0} \sum \mathrm{Xi}_{\mathrm{i}}+\mathrm{a}_{1} \sum \mathrm{Xi}^{2}=\sum \mathrm{XiY} \mathrm{P}
\end{gathered}
$$

Table 1 presented the analysis of peak load data of Addis North-01case study area. The six-year peak load data from 2015 to 2020 of the Addis North distribution feeders is collected and tabulated in Table 2.

Table 1. Analysis of peak load data of Addis North-01.

\begin{tabular}{ccccc}
\hline Year & $\mathbf{X i}$ & Peak Load $(\mathbf{M w})=\mathbf{Y}$ & $\mathbf{X i}^{\mathbf{2}}$ & $\mathbf{X i Y}$ \\
\hline 2015 & 1 & 7.37 & 1 & 7.37 \\
\hline 2016 & 2 & 7.99 & 4 & 15.98 \\
\hline 2017 & 3 & 8.73 & 9 & 26.19 \\
\hline 2018 & 4 & 9 & 16 & 36 \\
\hline 2019 & 5 & 8.09 & 25 & 40.45 \\
\hline 2020 & 6 & 10.42 & 36 & 62.52 \\
\hline & $\sum \mathrm{Xi}=21$ & $\sum \mathrm{Y}=51.6$ & $\sum \mathrm{Xi}^{2}=91$ & $\sum \mathrm{XiY}=188.51$ \\
\hline
\end{tabular}

Table 2. Feeder peak load demand data's from 2015 to $2020^{\prime}$ forecasted to 2030.

\begin{tabular}{ccccccccccccc}
\hline \multirow{2}{*}{ Year } & ADN1 & ADN2 & ADN3 & ADN4 & ADN5 & ADN1 & ADN2 & ADN3 & ADN4 & ADN5 \\
\cline { 2 - 10 } & \multicolumn{7}{c}{ Actual } & & & & \multicolumn{3}{c}{ Forecasted } \\
\hline 2015 & 7.37 & 9.74 & 7.13 & 5.79 & 8.98 & 7.52 & 9.95 & 7.25 & 5.7 & 8.69 \\
\hline 2016 & 7.99 & 10.84 & 7.3 & 6.06 & 9.08 & 7.91 & 10.17 & 7.63 & 5.96 & 8.78 \\
\hline 2017 & 8.73 & 9.94 & 8.11 & 5.71 & 8.33 & 8.33 & 10.39 & 8.03 & 6.23 & 8.88 \\
\hline 2018 & 9 & 10.44 & 9.62 & 6.95 & 8.48 & 8.77 & 10.62 & 8.44 & 6.51 & 8.97 \\
\hline 2019 & 8.09 & 11.06 & 8.63 & 6.68 & 9.15 & 9.23 & 10.86 & 8.88 & 6.8 & 9.07 \\
\hline 2020 & 10.42 & 11.11 & 8.88 & 7.15 & 9.6 & 9.72 & 11.10 & 9.34 & 7.11 & 9.17 \\
\hline 2021 & - & - & - & - & - & 10.23 & 11.35 & 9.83 & 7.43 & 9.27 \\
\hline 2022 & - & - & - & - & - & 10.77 & 11.60 & 10.3 & 7.76 & 9.37 \\
\hline 2023 & - & - & - & - & - & 11.34 & 11.85 & 10.9 & 8.11 & 9.47 \\
\hline 2024 & - & - & - & - & - & 11.94 & 12.12 & 11.4 & 8.48 & 9.57 \\
\hline 2025 & - & - & - & - & - & 12.57 & 12.39 & 12 & 8.86 & 9.67 \\
\hline 2026 & - & - & - & - & - & 13.23 & 12.66 & 12.7 & 9.26 & 9.78 \\
\hline
\end{tabular}


Table 2. Cont.

\begin{tabular}{|c|c|c|c|c|c|c|c|c|c|c|}
\hline \multirow{2}{*}{ Year } & ADN1 & ADN2 & ADN3 & ADN4 & ADN5 & ADN1 & ADN2 & ADN3 & ADN4 & ADN5 \\
\hline & \multicolumn{5}{|c|}{ Actual } & \multicolumn{5}{|c|}{ Forecasted } \\
\hline 2027 & - & - & - & - & - & 13.93 & 12.94 & 13.3 & 9.68 & 9.88 \\
\hline 2028 & - & - & - & - & - & 14.66 & 13.23 & 14 & 10.11 & 9.99 \\
\hline 2029 & - & - & - & - & - & 15.44 & 13.52 & 14.7 & 10.57 & 10.1 \\
\hline 2030 & - & - & - & - & - & 16.25 & 13.82 & 15.5 & 11.05 & 10.2 \\
\hline
\end{tabular}

The linear model for Addis north-01 becomes

$$
\begin{gathered}
\mathrm{Yi}=a_{0}+a_{1} \\
\mathrm{Xi} \mathrm{Yi}_{\mathrm{i}}=7.018+0.452 \times \mathrm{Xi}
\end{gathered}
$$

where, $\mathrm{a}_{0}$ is $7.018, \mathrm{a}_{1}$ is 0.452 and $\mathrm{Yi}$ is the forecasted demand value.

Using the listed square approximation methods, the peak load of the Addis North distribution feeders is forecasted for the year 2030 based on the six-year collection date. Table 2 displays the case study feeder peak load demand data from 2015 to 2020 forecasted for 2030 .

\section{Result and Discussion}

The load flow analysis of the existing network shows that the majority of the bus voltage of the feeder is out of the allowable limit, which is indicated by the blue color that is less than 0.95 p.u., and is shown in Figure 5. Additionally, the red color in Figure 5 shows the voltage profiles of the existing network on forecasted load demand and most of the bus voltages are out of permissible limits with the minimum voltage occurring at bus 29 , which was 0.873 p.u. Hence, the feeder has a poor voltage profile which indicates that additional means of voltage profile improvement are required.

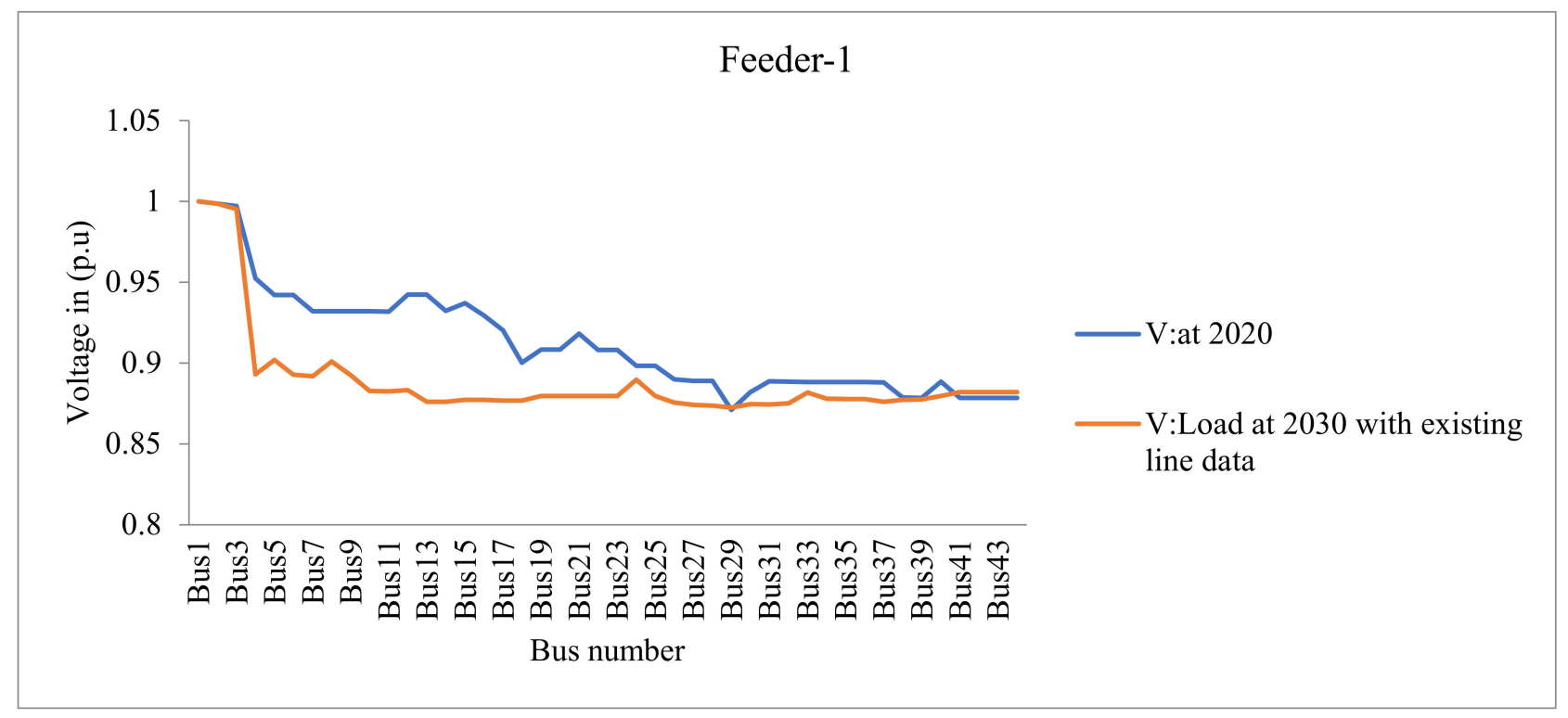

Figure 5. Existing Addis North feeder-1 network voltage profiles on existing and forecasted load. 


\subsection{Existing Power Distribution System Assessment Up to 2030}

In the years 2020 and 2030, Table 3 shows the outcomes of the existing network in the event of a peak load. Table 3 shows the outcomes of the existing network in the event of a peak load for the year 2020and 2030.

Table 3. Results of the existing network at peak demand in 2020 and 2030.

\begin{tabular}{|c|c|c|c|c|c|c|c|}
\hline $\begin{array}{l}\text { Feeder } \\
\text { Name }\end{array}$ & $\begin{array}{l}\text { Demand at } \\
2020 \text { (MW) }\end{array}$ & $\begin{array}{l}\text { Line } \\
\text { Data }\end{array}$ & Demand & $P_{\text {Loss }}(\mathrm{kW})$ & $\begin{array}{c}Q_{\text {Loss }} \\
\text { (kVAr) }\end{array}$ & $\begin{array}{l}\text { Overloaded } \\
\text { Lines }\end{array}$ & $\begin{array}{l}\text { Overloaded } \\
\text { Transformers }\end{array}$ \\
\hline \multirow{2}{*}{ ADN-01 } & \multirow{2}{*}{10.42} & \multirow{2}{*}{ At 2020} & At 2020 & 320.9 & 184.2 & Yes & Yes \\
\hline & & & At 2030 & 542.0 & 397.4 & Yes & Yes \\
\hline
\end{tabular}

\subsection{Upgraded and Added Conductor Lines and Distribution Substation (Transformer)}

For the year 2020, the required existing conductors and transformers sizes are tabulated in Tables 4 and 5, respectively. As stated in Table 4, the optimal conductor size is determined by the amount of current passing through the conductors as a result of the load flow.

Table 4. Upgraded conductors of existing feeders in case of demand in 2030GC.

\begin{tabular}{ccccc}
\hline $\begin{array}{c}\text { Name of the } \\
\text { Feeder }\end{array}$ & \multicolumn{2}{c}{ Type of Existing Conductor } & \multicolumn{2}{c}{ Type of Upgraded Conductor } \\
\hline & & Length $(\mathrm{km})$ & Length $(\mathrm{km})$ \\
\cline { 2 - 4 } & \multirow{2}{*}{ AAAC-150 } & 3.16 & AAAC_200 & 0.67 \\
\cline { 2 - 4 } & & & AAAC_400 & 0.45 \\
\cline { 2 - 4 } ADN-01 & AAAC_120 & AAAC_400 & 0.74 \\
\cline { 2 - 5 } & AAAC_95 & 0.1 & AAAC_200 & 0.1 \\
\cline { 2 - 4 } & & & AAAC_200 & 0.63 \\
\hline
\end{tabular}

Table 5. Upgraded transformers in case of demand of 2030GC.

\begin{tabular}{ccccccccccc}
\hline \multirow{2}{*}{ Year } & \multicolumn{4}{c}{ Transformer Rating (kVA) } & \multicolumn{4}{c}{ Total (MVA) } \\
\cline { 2 - 11 } & $\mathbf{2 5}$ & $\mathbf{5 0}$ & $\mathbf{1 0 0}$ & $\mathbf{2 0 0}$ & $\mathbf{3 1 5}$ & $\mathbf{4 0 0}$ & $\mathbf{5 0 0}$ & $\mathbf{6 3 0}$ \\
\hline Existing Transformers at 2020 & 3 & 4 & 3 & 6 & 18 & 3 & 1 & 7 & 13.555 \\
\hline Transformers at 2030 & ----- & ---- & --- & 3 & 9 & 12 & 13 & 8 & 19.775 \\
\hline
\end{tabular}

Most of the transformers are overloaded at this point, and they must be replaced with new ones with capacities calculated such that they can run at a maximum load in 2030GC. The new capacities of distribution substations (transformers) are selected based on the expected load in 2030GC, as shown in Table 5.

The power loss decreased considerably as a result of the load flow study, as shown in Table 6, although the system is still overloaded for the target year, 2030GC. The voltage profiles of the upgraded conductors are also improved in Figure 6, however, the majority of the voltages are still beyond the permitted standard voltage limits, indicating that they still need to be improved.

Table 6. Load flow results for upgraded existing network in peak load in 2030GC.

\begin{tabular}{ccccccc}
\hline Feeder & Line Data & Demand & P Loss $_{\text {(kW) }}$ & $\begin{array}{c}\text { Q Loss } \\
\text { (kVAr) }\end{array}$ & $\begin{array}{c}\text { Overload } \\
\text { Line }\end{array}$ & $\begin{array}{c}\text { Overload } \\
\text { Transformer }\end{array}$ \\
\hline Feeder-1 & Upgraded & At 2030 & 372.1 & 272.5 & No & No \\
\hline
\end{tabular}




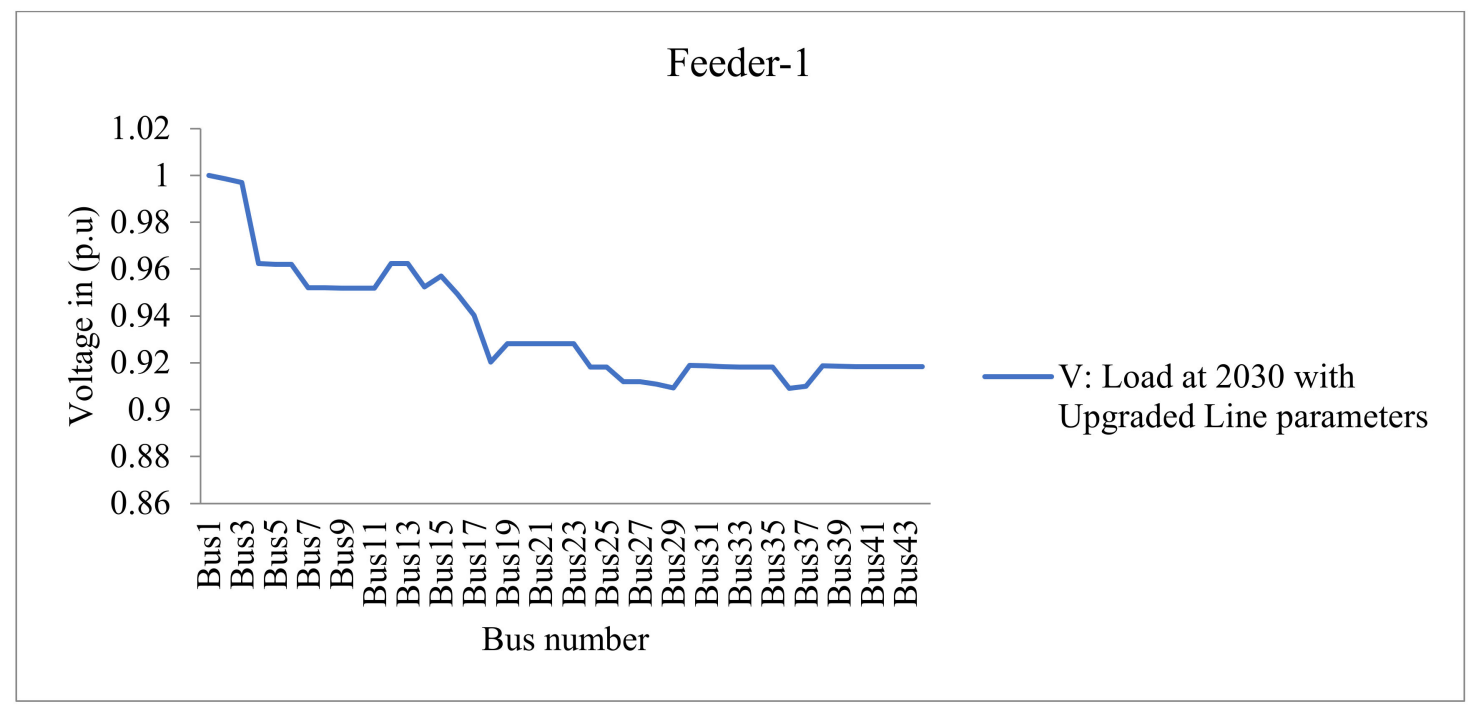

Figure 6. Voltage profiles of Addis north upgraded feeder-1 distribution network.

\subsection{DG Integration on the Upgraded Existing Network}

The appropriate DG sizing at all buses of the Addis North distribution network feeder- 1 is as shown in Figure 7 below.

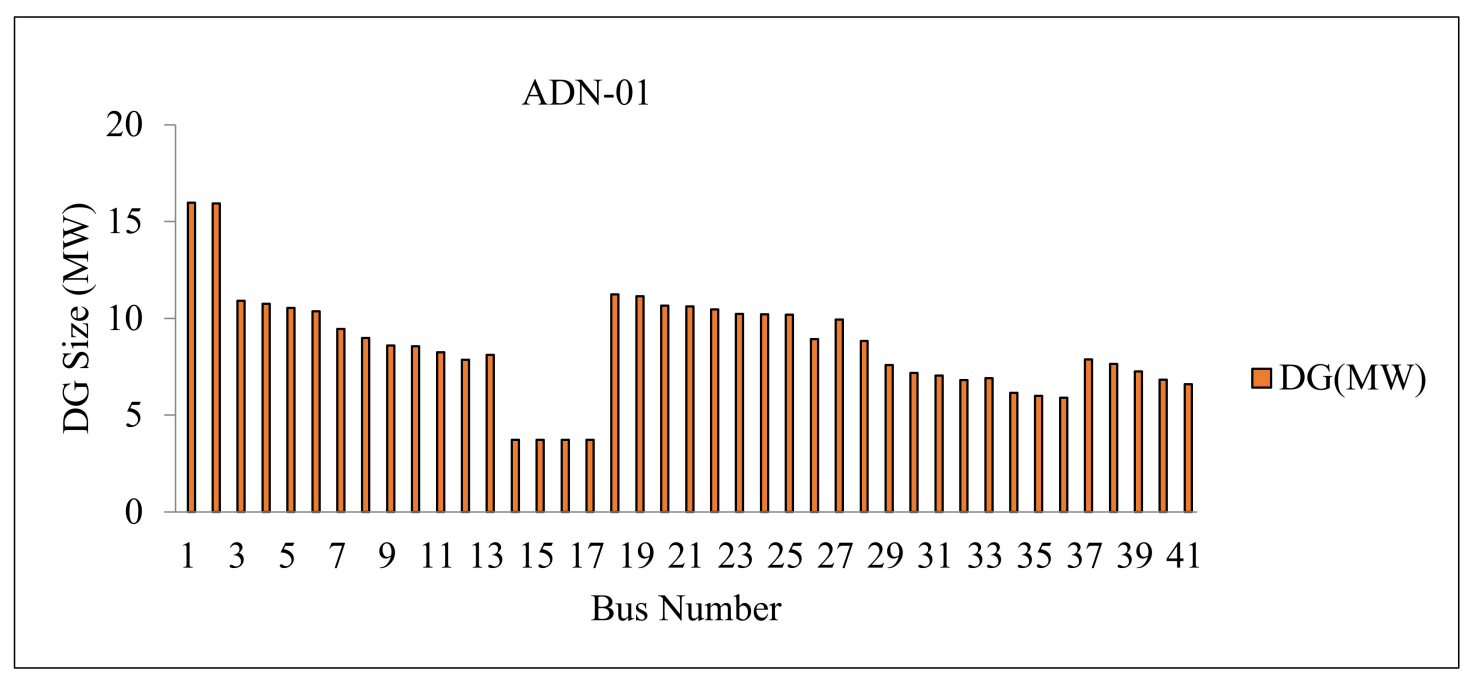

Figure 7. DG sizing on the upgraded existing feeder-1 in case of peak load in 2030GC.

\subsubsection{DG Integration on the Upgraded Existing Network}

Figure 8 below shows the power loss results when optimal sizes of DG are placed at its optimal location of Addis North feeder-1. The bus at which the total losses were minimum, which means the maximum total loss reduction of the feeder had been found, was considered as the proper location of DG.

For each study case, the total real and reactive power loss when DG units of the corresponding size were placed at each bus, is illustrated in Figure 8 above. For each study case, the balanced and positive sequence load flow analysis was executed and the minimum total real and reactive power loss was found at bus 29 , which was $0.2939 \mathrm{MW}$ and $0.219 \mathrm{MVAr}$, respectively. At this bus, the maximum active power loss reduction and reactive power loss reduction were $21.285 \%$ and $19.633 \%$, respectively. Additionally, the maximum voltage improvement was found in an increment of $8.78 \%$ bus voltage when DG size of $9.93 \mathrm{MW}$ was placed at bus 29. Thus, on the predicted year 2030GC, DG powers can cover $61.12 \%$ of the feeder-1 power requirements 
(i.e., $61.12 \%$ of $16.25 \mathrm{MW}$ ). Figure 9 below shows the one-line diagram of the upgraded Addis North feeder-1 distribution network with the appropriate DG placement.

Feeder-1

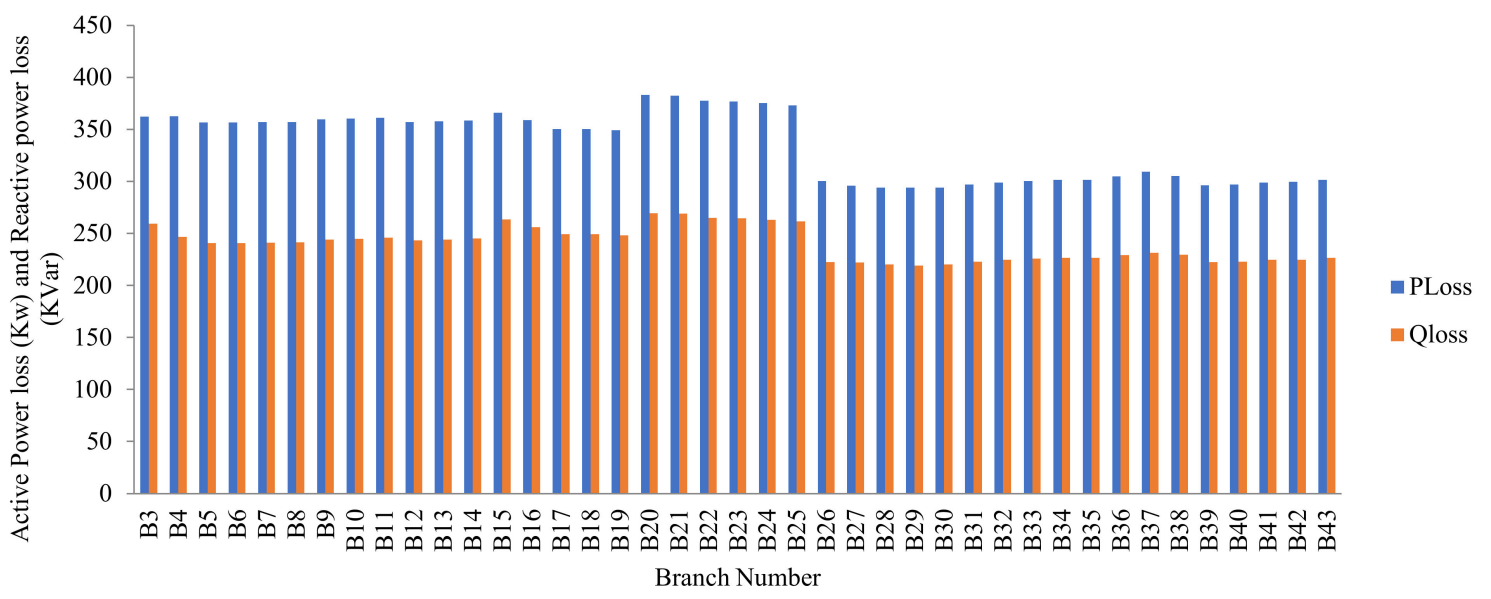

Figure 8. Active and reactive power loss when DG is integrated into Addis North feeder-1.

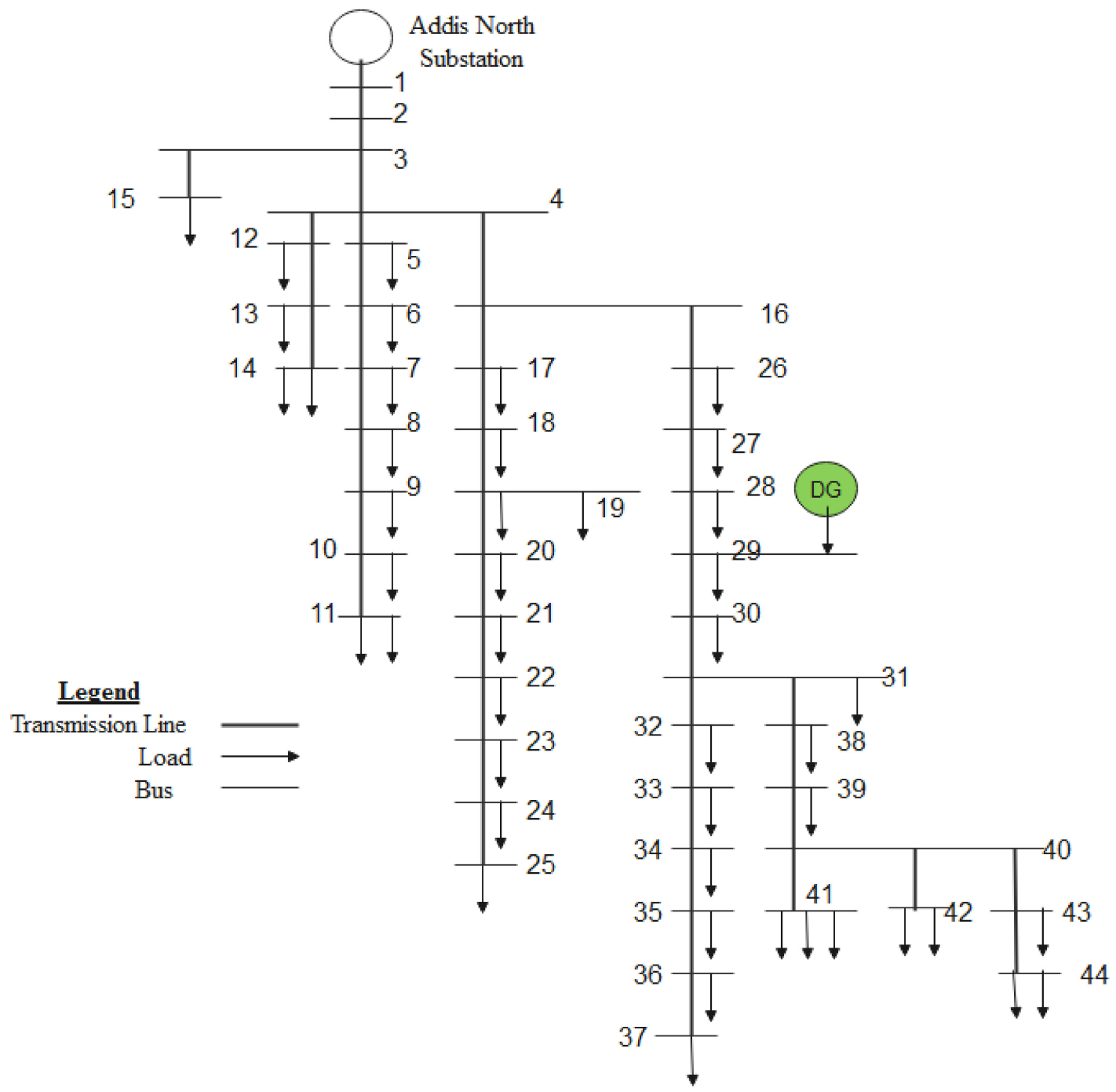

Figure 9. Single Line Diagram for Addis North-1with DG. 


\subsubsection{DG Impact on Voltage Profile}

The green color indicates the bus voltage profiles of the forecasted load of 2030GC with the upgraded Addis North feeder- 1 line parameters and when DG is placed at bus 29 . The minimum voltage magnitude which occurs at bus 29 was determined to be $0.90 \mathrm{p} . \mathrm{u}$, and then improved to 0.979 p.u. In integrating DG on the upgraded Addis North feeder-1 distribution network, the maximum increment in $8.78 \%$ of voltages was found at this bus.

The voltages on all buses were under acceptable limits following the incorporation of DG, according to the results. The existing distribution network's voltage profile was enhanced when compared to the system's voltage profile after DG integration to clearly highlight the improvement in the system's voltage profile. Figure 10 shows a comparison of the voltage profile on the old distribution network, the upgraded distribution network, and after DG integration, revealing that the voltage profile on all system buses has significantly improved.

\section{Feeder-1/ADN-1}

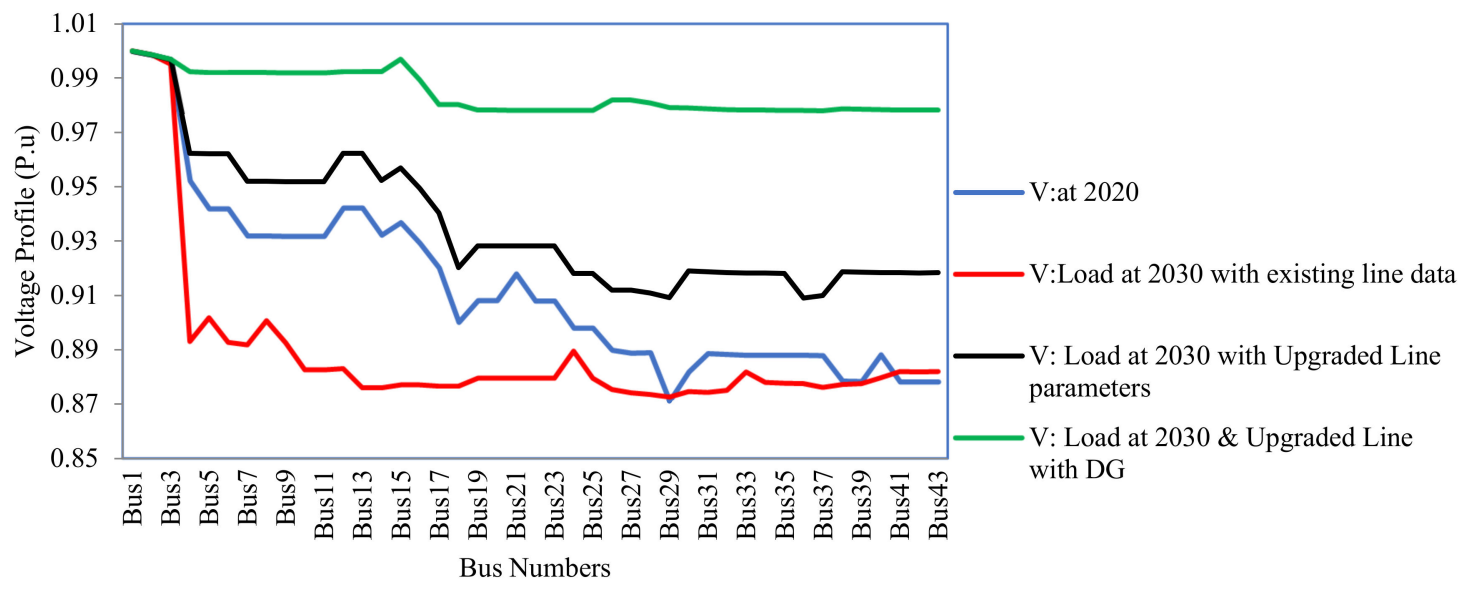

Figure 10. Voltage profiles of Addis North feeder-1 with different cases.

When proper unit sizing and location are taken into account, the impact of DG integration on the radial distribution system's voltage profile is often beneficial.

Generally, as shown in Figure 10 above, the analysis of existing networks was checked with the existing and forecasted peak load data. In this case, the distribution networks and transformers were overloaded, the voltage profiles were below acceptable limits and high power losses were recorded. Due to this overloaded equipment, the utility is vulnerable to high-reliability issues and is unable to supply adequate powers to the customers.

Thus, to increase the customers' satisfaction and to supply adequate clean electric energy, the long-term DNEP was carried out for Addis North feeder-1 distribution networks. Based on the forecasted peak load data for the year 2030, the distribution networks and transformer sizes were upgraded and the devices' overloading conditions of the utilities are minimized. The analysis of upgraded networks with forecasted peak load data of the year 2030 was performed. In this case, and as shown in Figure 10 above, the voltage profiles were below the acceptable standard ranges. To mitigate this problem, the DG at its optimal sizes and location were integrated at Addis North feeder-1 distribution networks. After the DG was integrated into the upgraded distribution networks, the voltage profiles were improved and their value was within acceptable ranges. 


\section{Conclusions}

The importance of long-term DNEP and the related long-term demand increase is highlighted in this study. The load flow analysis, electrical load demand forecasts, distribution network expansion planning, and ideal DG size and location of DG are explained in order to optimize the power loss and voltage profiles of the Addis North feeder-1 distribution network. The ETAP 16.0 simulation software was used for the feeder's modeling and simulation. According to the findings of this study, distribution network expansion planning with DG integration is recommended in order to ensure that growing load demand can be met while also overcoming deficiencies, such as transmission network overloading, transformer overloading, high power loss, and low-voltage profiles.

According to the simulation results, the existing feeder experienced a total real and reactive power loss of $0.524 \mathrm{MW}$ and 0.3974 MVAR at 2030GC with the predicted load demand. A distributed generator was installed in the system at the right location and size to reduce the overall real and reactive power loss of the system and to increase all node voltages to within the permitted range. The right location and size of DG were located and concluded to be at bus 29 with a proper size of $9.93 \mathrm{MW}$, and this size of DG can cover 61.12 percent of the power requirement of the load in the forecasted year 2030GC, based on the analytical method and load flow study, respectively.

The use of DG sizing and placement, as well as network upgrades, effectively reduces total active and reactive power losses by 21.285 percent and 19.633 percent, respectively. The voltage profile on the selected bus was also enhanced by 8.78 percent.

Author Contributions: Conceptualization, M.A.; methodology, M.A. and B.K.; software, M.A.; validation, M.A., B.K., I.G., N.G. and O.P.M.; formal analysis, B.K., M.K. N.G. and T.S.; investigation, M.A., M.K. and N.G.; resources, B.K.; data curation, B.K.; writing-original draft preparation, M.A.; writing-review and editing, B.K., M.K., N.G. and O.P.M.; visualization, B.K.; supervision, B.K. and T.S.; project administration, B.K. All authors have read and agreed to the published version of the manuscript.

Funding: This research received no external funding.

Data Availability Statement: Data will be available on request.

Acknowledgments: Authors acknowledged the support of their institutions.

Conflicts of Interest: The authors declare no conflict of interest.

\section{References}

1. Gómez-Expósito, A.; Conejo, A.J.; Cañizares, C. Electric Energy Systems. Analysis and Operation; CRC Press: Boca Raton, FL, USA, 2009.

2. El-Khattam, W.; Hegazy, Y.G.; Salama, M.M.A. An integrated distributed generation optimization model for distribution system planning. IEEE Trans. Power Syst. 2015, 20, 1158-1165. [CrossRef]

3. Farrag, M.A.; El-Metwally, M.M.; El-Bages, M.S. A new model for distribution system planning. Electr. Power Energy Syst. 2009, 21, 523-531. [CrossRef]

4. Willis, H.L. Power Distribution Planning Reference Book, 2nd ed.; Marcel Dekker: New York, NY, USA, $2014 ;$ p. 1217.

5. Pregelj, A.; Begovic, M.; Rohatgi, A. Recloser allocation for improved reliability of DG-enhanced distribution networks. IEEE Trans. Power Syst. 2016, 21, 1442-1449. [CrossRef]

6. Gil, H.A.; Joos, G. On the Quantification of the Network Capacity Deferral Value of Distributed Generation. IEEE Trans. Power Syst. 2006, 21, 1592-1599. [CrossRef]

7. Ahmadigorji, M.; Amjady, N. A multiyear DG-incorporated framework for expansion planning of distribution networks using binary chaotic shark smell optimization algorithm. Energy 2016, 102, 199-215. [CrossRef]

8. Zhang, C.; Ding, Y.; Wu, Q.; Wang, Q.; Østergaard, J. Distribution Network Expansion Planning Based on Multi-objective PSO Algorithm. Energy Power Eng. 2013, 5, 975-979. [CrossRef]

9. Nayeripour, M.; Saeed, H.; Hossein, F.-A. Optimal expansion planning of distribution system capacity with respect to distributed generations. Int. J. Renew. Energy Res. 2018, 6, 3.

10. Li, R.; Wang, W.; Chen, Z.; Jiang, J.; Zhang, W. A Review of Optimal Planning Active Distribution System: Models, Methods, and Future Researches. Energies 2017, 10, 1715. [CrossRef]

11. Minyou, H.; Yuan, C. Simulated annealing algorithm of optimal reconstruction in distribution system. Autom. Electr. Power Syst. 2009, 2

12. Najafi, S.; Shafie-Khah, M.; Hajibandeh, N.; Osório, G.J.; Catalão, J.P.S. A New DG Planning Approach to Maximize Renewable-Based DG Penetration Level and Minimize Annual Loss; Springer: Cham, Switzerland, 2017. 
13. Raut, U.; Mishra, S. Power distribution network reconfiguration for loss minimization using a new graph theory based genetic algorithm. In Proceedings of the 2017 IEEE Calcutta Conference (CALCON), Kolkata, India, 2-3 December 2017; pp. 1-5.

14. Tolba, M.A.; Tulsky, V.N.; Diab, A.A.Z. Optimal sitting and sizing of renewable distributed generations in distribution networks using a hybrid PSOGSA optimization algorithm. In Proceedings of the 2017 IEEE International Conference on Environment and Electrical Engineering and 2017 IEEE Industrial and Commercial Power Systems Europe (EEEIC/I\&CPS Europe), Milan, Italy, 6-9 June 2017; pp. 1606-1612.

15. Mohan, V.J.; Albert, T.A.D. Optimal Sizing and Sitting of Distributed Generation Using Particle Swarm Optimization Guided Genetic Algorithm. In Advances in Computational Sciences and Technology; Reseaech India Publications: Delhi, India, 2017; Volume 10, pp. 709-720.

16. Abdel-Mawgoud, H.; Kamel, S.; Ebeed, M.; Aly, M.M. An efficient hybrid approach for optimal allocation of DG in radial distribution networks. In Proceedings of the 2018 International Conference on Innovative Trends in Computer Engineering (ITCE), Aswan, Egypt, 19-21 February 2018; pp. 311-316.

17. Vidyasagar, S.; Vijayakumar, K.; Ramanujam, R.; Sattianadan, D.; Kumar, N. Voltage profile improvement using DG in reconfigured distribution system. Int. J. Control Autom. 2019, 8, 393-410. [CrossRef]

18. Nick, M.; Rachid, C.; Mario, P. Optimal planning of distributed energy storage systems in active distribution networks embedding grid reconfiguration. IEEE Trans. Power Syst. 2017, 99, 1. [CrossRef]

19. Sarfaraz; Bansal, A.; Singh, S. Optimal allocation and sizing of distributed generation for power loss reduction. In Proceedings of the International Conference \& Workshop on Electronics \& Telecommunication Engineering (ICWET 2016), Mumbai, India, 26-27 February 2016.

20. Haider, W.; Hassan, S.J.U.; Mehdi, A.; Hussain, A.; Adjayeng, G.O.M.; Kim, C.-H. Voltage Profile Enhancement and Loss Minimization Using Optimal Placement and Sizing of Distributed Generation in Reconfigured Network. Machines 2021, 9, 20. [CrossRef]

21. Podder, A.K.; Islam, S.; Kumar, N.M.; Chand, A.A.; Rao, P.N.; Prasad, K.A.; Logeswaran, T.; Mamun, K.A. Systematic categorization of optimization strategies for virtual power plants. Energies 2020, 13, 6251. [CrossRef]

22. Badar, E.; Islam, U. Comparison of conventional and modern load forecasting techniques based on artificial intelligence and expert systems. Int. J. Comput. Sci. Issues 2016, 8, 504-513.

23. Singh, A.K.; Khatoon, I.S.; Muazzam, M. An overview of electricity demand forecasting techniques. Netw. Complex Syst. 2013, 3, 38-48.

24. Ang, S.; Leeton, U. Optimal placement and size of distributed generation in radial distribution system using whale optimization algorithm. Suranaree J. Sci. Technol. 2019, 1, 26.

25. Bashir, A.; Khan, J.; Rana, A.; Junaid, M.; Mansoor Asghar, M. ETAP software based transient, ground grid and short circuit analyses of $132 \mathrm{kV}$ grid. AIP Conf. Proc. 2010, 1239, 25-30.

26. Sa'ed, J.A.; Amer, M.; Bodair, A.; Baransi, A.; Favuzza, S.; Zizzo, G. A Simplified Analytical Approach for Optimal Planning of Distributed Generation in Electrical Distribution Networks. Appl. Sci. 2019, 9, 5446. [CrossRef]

27. Patel, M.R. Wind and Solar Power Systems: Design, Analysis, and Operation; CRC Press: Boca Raton, FL, USA, 2015.

28. Pandey, D.; Bhadoriya, J.S. Optimal placement \& sizing of distributed generation (DG) to minimize active power loss using particle swarm optimization (PSO). Int. J. Sci. Technol. Res. 2014, 3, 246-254.

29. Mahmoud, K.; Lehtonen, M. Simultaneous allocation of multi-type distributed generations and capacitors using generic analytical expressions. IEEE Access 2019, 16, 182701-182710. [CrossRef]

30. Murty, V.V.; Kumar, A. Optimal DG integration and network reconfiguration in microgrid system with realistic time varying load model using hybrid optimization. IET Smart Grid. 2019, 2, 192-202. [CrossRef]

31. Hosseini, S.A.; Madahi, S.S.K.; Razavi, F.; Karami, M.; Ghadimi, A.A. Optimal sizing and siting of distributed generation resources using a multiobjective algorithm. Turk. J. Electr. Eng. Comput. Sci. 2015, 21, 825-850.

32. Kersting, W.H.; Fellow, L.; Green, R.K.; Member, L.S. The Application of Carson's Equation to the Steady-State Analysis of Distribution Feeders. In Proceedings of the 2011 IEEE/PES Power Systems Conference and Exposition, Phoenix, AZ, USA, 20-23 March 2011; pp. 1-6. 